\title{
Changing epidemiology of meticillin-resistant Staphylococcus aureus in 42 hospitals in the Dutch- German border region, 2012 to 2016: results of the search-and-follow-policy
}

Annette Jurke ${ }^{1}$, Inka Daniels-Haardt², Welmoed Silvis³, Matthijs S. Berends ${ }^{4,5}$, Corinna Glasner5, Karsten Becker6, Robin Köck ${ }^{6,7,8}$, Alex W. Friedrich 5

1. North Rhine-Westphalian Centre for Health, Section Infectious Disease Epidemiology, Bochum, Germany

2. North Rhine-Westphalian Centre for Health, Department Health Promotion, Health Protection, Bochum, Germany

3. Laboratory for Medical Microbiology and Public Health (LabMicTA), Hengelo, Netherlands

4. Certe Medical Diagnostics and Advice, Groningen, Netherlands

5. University of Groningen, University Medical Center Groningen, Department of Medical Microbiology and Infection Prevention, Groningen, Netherlands

6. University Hospital Münster, University of Münster, Institute of Medical Microbiology, Münster, Germany

7. University Hospital Münster, University of Münster, Institute for Hygiene, Münster, Germany

8. Institute of Hygiene, DRK Kliniken Berlin, Berlin, Germany

Correspondence: Anette Jurke (annette.jurke@lzg.nrw.de)

Jurke Annette, Daniels-Haardt Inka, Silvis Welmoed, Berends Matthijs S., Glasner Corinna, Becker Karsten, Köck Robin, Friedrich Alex W.. Changing epidemiology of meticillin-resistant Staphylococcus aureus in 42 hospitals in the Dutch-German border region, 2012 to 2016: results of the search-and-follow-policy. Euro Surveill. 2019;24(15):pii=1800244. https://doi.org/10.2807/1560-7917.ES.2019.24.15.1800244

Introduction: Meticillin-resistant Staphylococcus aureus (MRSA) is a major cause of healthcare-associated infections. Aim: We describe MRSA colonisation/infection and bacteraemia rate trends in Dutch-German border region hospitals (NL-DE-BRH) in 2012-16. Methods: All 42 NL-DE BRH (8 NL-BRH, $34 \mathrm{DE}-\mathrm{BRH})$ within the cross-border network EurSafety Health-net provided surveillance data (on average ca 620,000 annual hospital admissions, of these $68.0 \%$ in Germany). Guidelines defining risk for MRSA colonisation/infection were reviewed. MRSA-related parameters and healthcare utilisation indicators were derived. Medians over the study period were compared between NL- and DE-BRH. Results: Measures for MRSA cases were similar in both countries, however defining patients at risk for MRSA differed. The rate of nasopharyngeal MRSA screening swabs was 14 times higher in DE-BRH than in NL-BRH (42.3 vs 3.0/100 inpatients; $p<0.0001)$. The MRSA incidence was over seven times higher in DE-BRH than in NL-BRH (1.04 vs 0.14/100 inpatients; $p<0.0001$ ). The nosocomial MRSA incidence-density was higher in DE-BRH than in NL-BRH (0.09 vs $0.03 / 1,000$ patient days; $p=0.0002$ ) and decreased significantly in DE-BRH $(p=0.0184)$ during the study. The rate of MRSA isolates from blood per 100,000 patient days was almost six times higher in DE-BRH than in NL-BRH (1.55 vs $0.26 ; p=0.0041)$. The patients had longer hospital stays in DE-BRH than in NL-BRH (6.8 vs 4.9 ; $p<0.0001)$. DE-BRH catchment area inhabitants appeared to be more frequently hospitalised than their Dutch counterparts. Conclusions: Ongoing IPC efforts allowed MRSA reduction in DE-BRH. Besides IPC, other local factors, including healthcare systems, could influence MRSA epidemiology.

\section{Introduction}

Cross-border patient mobility is a priority in the European Union (EU), because the most accessible or appropriate care for citizens living in border regions may be available abroad. When, in 2013, the directive 2011/24/EU came into force, patients' right to access healthcare in other Member States including reimbursement and medical follow-up in their respective home countries was entitled in an EU law for the first time. With this, cross-border cooperation in infection prevention and control (IPC) using comprehensive strategies is important [1].

Antimicrobial resistant (AMR) pathogens are a serious threat to public health in Europe, leading to increased healthcare costs, treatment failure and deaths. For invasive bacterial infections, prompt treatment with effective antimicrobial agents is essential and is one of the most effective interventions to reduce the risk of fatal outcomes [2]. Currently, the epidemiological situation is cause for concern especially with regard to AMR Gramnegative pathogens, e.g. characterised by carbapenem resistance (CR) [3]. However, the Gram-positive meticillin-resistant Staphylococcus aureus (MRSA) is still one 


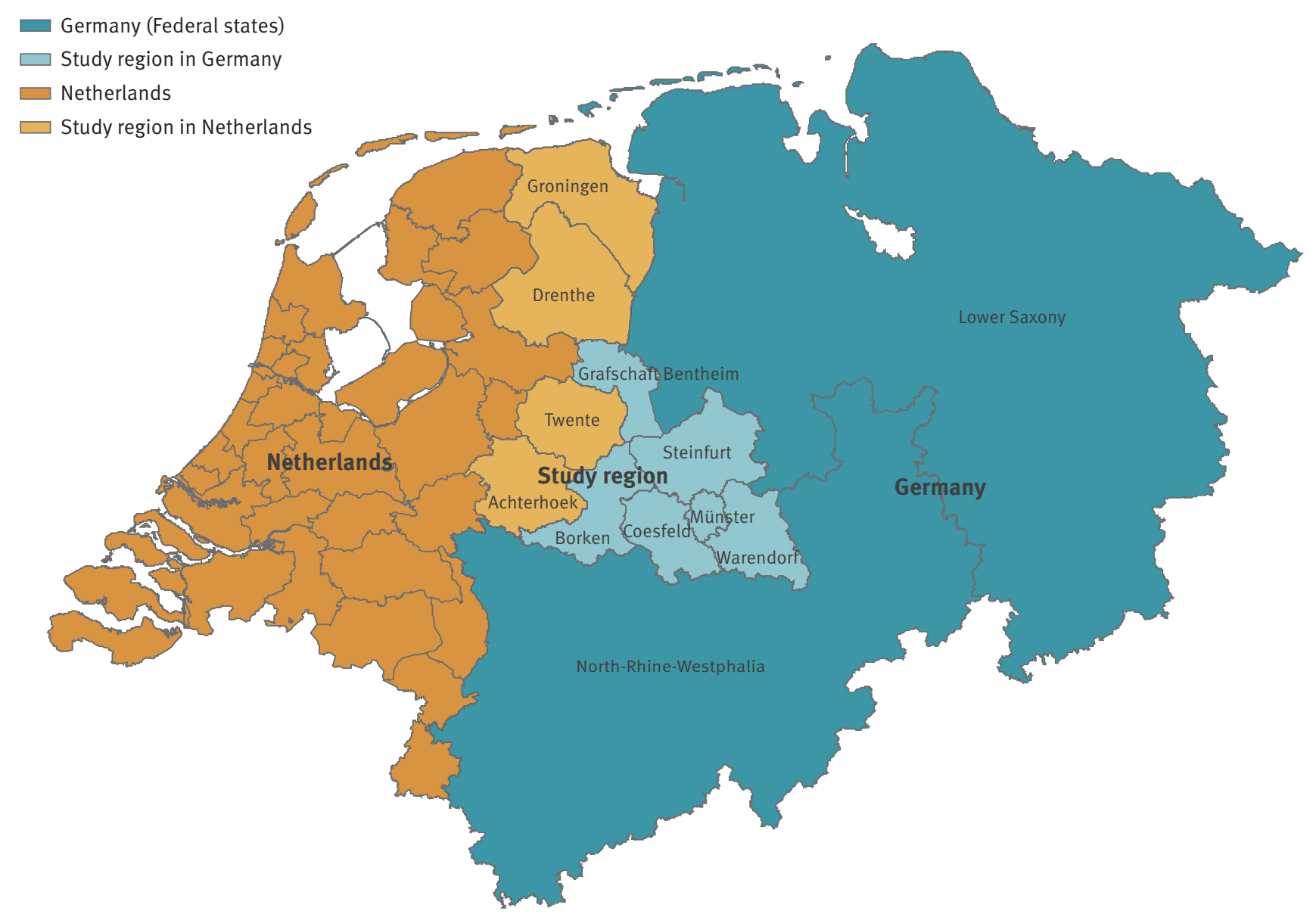

The light orange area represents the study region within the Netherlands, including the Dutch regions East Groningen (NL111), Delfzijl and surroundings (NL112), rest of Groningen (NL113), North Drenthe (NL 131), South East Drenthe (NL132), South West Drenthe (NL133), Twente (NL213), Achterhoek (NL225). The light blue area represents the study region within Germany, including the Grafschaft Bentheim region (DE94B) and the Münsterland-region with the urban district Münster (DEA33) and the rural districts Borken (DEA34), Coesfeld (DEA35), Steinfurt (DEA37) and Warendorf (DEA38).

of the most important causes of healthcare-associated infections due to AMR pathogens [3].

In 2017 in a consensus report of the European Centre for Disease Prevention and Control (ECDC), the European Food Safety Authority (EFSA) and the European Medicines Agency (EMA), the proportion of MRSA in invasive $S$. aureusinfections was proposed as an indicator for surveillance of AMR pathogens in humans [4]. Although in 2016 the proportion of MRSA in invasive S. aureus infections in Europe reached its lowest level (13.7\%) since the ECDC first presented population-weighted data for the EU in 2009, large inter-country variations (1.2 to $50.5 \%$ ) remain in Europe [3]. For example, in the most populated German federal state, North Rhine-Westphalia (NRW), the incidence of MRSA bacteraemia per inhabitants was 32-fold higher compared with the Dutch neighbouring region with similar population size in 2009-10 [5].
The occurrence of MRSA still necessitates continuous surveillance and preparedness to optimise IPC to further decrease MRSA rates [6-9]. Since 1999, MRSA screening of various sites including at least nares, phar$\mathrm{ynx}$ and wounds (if present) and additionally perineum or groin (in case of known previous carriage) before or at admission to hospitals is recommended in Germany, if patients have defined risk factors [10]. For MRSA carriers IPC measures including isolation in single rooms, barrier precautions and decolonisation therapies are also recommended $[10,11]$. Within the EU-funded community initiative INTERREG IIIA in 2006, all hospitals in the German Münsterland region, located directly at the Dutch-German border, started to establish a network to control MRSA - the EUREGIO MRSA net. They agreed to monitor the implementation of the IPC measures, harmonise local standards, exchange hospital utilisation data and MRSA data, perform molecular typing of 
TABLE 1

Risk factors for MRSA carriage at admission according to Dutch and German MRSA guidelines, 2012-2016

\begin{tabular}{|c|c|c|}
\hline \multirow{2}{*}{ MRSA carriage risk factors } & \multicolumn{2}{|c|}{ Defined risk factors for MRSA screening according to national guideline/recommendation } \\
\hline & Germany & Netherlands \\
\hline \multirow{3}{*}{$\begin{array}{l}\text { (Previous) MRSA carriage or } \\
\text { infection }\end{array}$} & \multirow{3}{*}{$\begin{array}{l}\text { Known MRSA carrier or previous MRSA } \\
\text { carriage or infection }\end{array}$} & Known MRSA carrier (RMRSA) \\
\hline & & $\begin{array}{c}\text { (Previous) MRSA carrier who underwent decolonisation, } \\
\text { without three consecutive negative MRSA screening tests, } \\
\text { taken at least } 7 \text { days apart (RMRSA) }\end{array}$ \\
\hline & & $\begin{array}{c}\text { (Previous) MRSA carrier who underwent decolonisation, } \\
\text { with three consecutive negative MRSA screening tests, } \\
\text { taken at least } 7 \text { days apart, and is within } 1 \text { year follow-up } \\
\text { after first negative MRSA test (RL) }\end{array}$ \\
\hline \multirow{4}{*}{ Contact to MRSA positive person } & \multirow{4}{*}{$\begin{array}{l}\text { Contact with another person with MRSA } \\
\text { carriage or infection (same room) }\end{array}$} & $\begin{array}{l}\text { Unprotected contact within the last } 2 \text { months: } \\
\text { - Inside hospital: part of ring investigation (RH) }\end{array}$ \\
\hline & & $\begin{array}{l}\text { - Outside hospital: household member, partner or } \\
\text { caregiver of MRSA positive person }(\mathrm{RH})^{\mathrm{a}}\end{array}$ \\
\hline & & $\begin{array}{c}\text { - Contact to MRSA positive healthcare worker, regardless } \\
\text { of duration (RL) }\end{array}$ \\
\hline & & \begin{tabular}{|c} 
Persistent unprotected exposure: negative MRSA screening \\
test within the last 3 months (RL) \\
\end{tabular} \\
\hline \multirow{4}{*}{$\begin{array}{l}\text { Recent stay in other healthcare } \\
\text { institution }\end{array}$} & \multirow{3}{*}{$\begin{array}{l}\text { Hospitalisation for }>3 \text { days within the } \\
\text { previous } 12 \text { months }\end{array}$} & $\begin{array}{c}\text { Stayed in a foreign healthcare institution within the last } 2 \\
\text { months }(\mathrm{RH}) \text {, and: } \\
\text { - stayed more than } 24 \text { hours, or }\end{array}$ \\
\hline & & $\begin{array}{l}\text { - stayed less than } 24 \text { hours plus at least one secondary } \\
\text { risk factor (invasive procedure, chronic infections, } \\
\text { persistent skin lesions, abscesses or furuncles) for MRSA } \\
\text { carriage }\end{array}$ \\
\hline & & $\begin{array}{c}\text { Stayed in a foreign healthcare institution more than } 2 \\
\text { months ago plus at least one secondary risk factor (see } \\
\text { above) for MRSA carriage (RL) }\end{array}$ \\
\hline & $\begin{array}{c}\text { Direct transfer of the patient from } \\
\text { facilities in regions with known high MRSA } \\
\text { prevalence (i.e. including all German } \\
\text { healthcare facilities) }\end{array}$ & $\begin{array}{l}\text { Previous hospitalisation within the last two months in } \\
\text { a Dutch healthcare institution in a department with an } \\
\text { ongoing MRSA outbreak (RH) }\end{array}$ \\
\hline Haemodialysis patients & All haemodialysis patients ${ }^{\mathrm{b}}$ & $\begin{array}{c}\text { - Patient usually dialysed abroad (i.e. 'home dialysis } \\
\text { center' abroad), now dialysed in the Netherlands (i.e. } \\
\text { guest dialysis patients) (RH) } \\
\text { - Patient usually dialysed in the Netherlands (i.e. Dutch } \\
\text { 'home dialysis center') dialysed abroad within the last two } \\
\text { months (RL) }\end{array}$ \\
\hline Contact to livestock & $\begin{array}{l}\text { Regular professional direct contact to } \\
\text { livestock (swine, cattle, poultry)c }\end{array}$ & $\begin{array}{c}\text {-Contact to live pigs/meat calves/broilers }{ }^{c} \text { regardless of } \\
\text { whether this contact was professional or not and/or lives } \\
\text { on a farm where these animals are kept }(\mathrm{RH}) \\
\text { - Persistent exposure: negative MRSA screening test within } \\
\text { the last } 3 \text { months }(\mathrm{RL})\end{array}$ \\
\hline \multirow[b]{2}{*}{ Other risk factors } & Chronic skin lesions & \multirow{2}{*}{$\begin{array}{l}\text { - Children adopted from abroad and living in the } \\
\text { Netherlands (RH) } \\
\text { - Stayed in a home for asylum seekers within the last two } \\
\text { months }(\mathrm{RH})^{\mathrm{d}}\end{array}$} \\
\hline & $\begin{array}{l}\text { Need for long-term care plus one of } \\
\text { the following risk factors }{ }^{\mathrm{b}}:(\mathrm{i}) \text { receipt of } \\
\text { antibiotics during the previous } 6 \text { months, } \\
\text { or (ii) presence of indwelling devices }\end{array}$ & \\
\hline
\end{tabular}

MRSA: meticillin-resistant Staphylococcus aureus; RMRSA/RH/RL: risk categories corresponding to different levels of isolation for inpatients.

${ }^{a}$ Added in December 2012.

${ }^{b}$ Modified in 2012-13: patient with two or more of the following risk factors: need for long-term care, receipt of any antibiotics during the previous six months, presence of indwelling devices, need for haemodialysis, skin lesions and burns.

'Modified; in 2012-13 only swine.

${ }^{\mathrm{d}}$ Added in October 2015.

The levels of isolation for inpatients with risk categories were the following: (RMRSA) MRSA positive- or (RH) high-risk category patients in high-risk departments of the hospital (e.g. intensive care unit, haematology): single room isolation with contact- and airborne precautions. (RH) High-risk category patients who are not in high risk departments and who have an MRSA screening result available within 24 hours of admission: single room with contact precaution. (RL) Low-risk category: no isolation, awaiting new MRSA screening test results. 
Numbers of meticillin-resistant Staphylococcus aureus cases documented in all study hospitals in the German region of Münsterland and the Dutch regions of Twente-Achterhoek, Drenthe and Groningen, 2012-2016 ( $\mathrm{n}=42$ hospitals) ${ }^{\mathrm{a}}$

\begin{tabular}{|c|c|c|c|c|c|c|c|c|c|c|c|}
\hline \multirow{3}{*}{ Region, country (number of BRH) } & \multirow{3}{*}{ MRSA cases } & \multicolumn{10}{|c|}{ Year } \\
\hline & & \multicolumn{2}{|c|}{2012} & \multicolumn{2}{|c|}{2013} & \multicolumn{2}{|c|}{2014} & \multicolumn{2}{|c|}{2015} & \multicolumn{2}{|c|}{2016} \\
\hline & & $\mathrm{n}$ & $\%$ & $\mathrm{n}$ & $\%$ & $\mathrm{n}$ & $\%$ & $\mathrm{n}$ & $\%$ & $\mathrm{n}$ & $\%$ \\
\hline \multirow{3}{*}{$\begin{array}{l}\text { Münsterland, Germany } \\
\text { (34 DE-BRH) }\end{array}$} & MRSA (total) & 4,453 & 100.0 & 4,481 & 100.0 & 4,391 & 100.0 & 4,418 & 100.0 & 4,122 & 100.0 \\
\hline & Nosocomial MRSA cases ${ }^{b}$ & 430 & 9.7 & 361 & 8.1 & 316 & 7.2 & 266 & 6.0 & 260 & 6.3 \\
\hline & MRSAB cases & 72 & NA & 93 & NA & 53 & NA & 56 & NA & 60 & NA \\
\hline \multirow{4}{*}{$\begin{array}{l}\text { Twente-Achterhoek/Drenthe/ } \\
\text { Groningen, Netherlands } \\
(8 \mathrm{NL}-\mathrm{BRH})^{\mathrm{a}}\end{array}$} & MRSA (total) & 216 & 100.0 & 295 & 100.0 & 308 & 100.0 & 321 & 100.0 & 327 & 100.0 \\
\hline & $\begin{array}{l}\text { MRSA cases with known } \\
\text { status imported or } \\
\text { nosocomial }\end{array}$ & 77 & 35.6 & 133 & 45.0 & 134 & 43.5 & 143 & $44 \cdot 5$ & 133 & 40.7 \\
\hline & Nosocomial MRSA cases ${ }^{b}$ & 10 & $13.0^{\mathrm{b}}$ & 16 & $12.0^{\mathrm{b}}$ & 22 & $16.4^{\mathrm{b}}$ & 18 & $12.6^{\mathrm{b}}$ & 14 & $10.5^{b}$ \\
\hline & MRSAB cases & 5 & NA & 12 & NA & 11 & NA & 12 & NA & 3 & NA \\
\hline
\end{tabular}

DE-BRH: German border region hospitals; MRSA: meticillin-resistant Staphylococcus aureus; MRSAB: MRSA isolated from blood cultures; NA: not applicable; NL-BRH: Dutch border region hospitals.

a From 2015 onwards, the number of DE-BRH was reduced to 33 . This implies that the total number of hospitals in the study region became 41 after 2015.

b Data about the classification of cases as 'nosocomial' or 'imported' were only available for German hospitals, Dutch hospitals in the Twente-Achterhoek region and since 2013, for one hospital in Groningen, Netherlands. The given percentages refer to the percentages of nosocomial cases among those MRSA cases for whom this information was documented.

MRSA isolates and establish regional benchmarks [12]. This 'search-and-follow' strategy was inspired from the 'search-and-destroy' policy implemented in Dutch hospitals since the 1980s. It aimed to improve application of the German national MRSA recommendations, the regional cooperation between hospitals, other healthcare facilities and public health authorities, as well as to create a more robust MRSA surveillance system [9,12-14]. Further to this strategy, screening for MRSA carriage among risk patients at hospital admission increased between 2009 and 2011 in these regional German hospitals and the nosocomial MRSA incidence density significantly decreased [15].

The cross-border IPC network cooperation, i.e. the Dutch-German web-based communication portal for handling MRSA problems for healthcare workers, patients and the public was continued from 2009 to 2015 within the INTERREG IVA funded project EurSafety Health-net. This enabled hospitals and nursing homes to acquire Euregional Quality and Transparency certificates. Moreover, since 2016, the collaboration was further prolonged within the INTERREG VA funded project EurHealth-1Health inter alia. Within this, the Dutch signaling meeting of the Hospital-acquired Infection and Antimicrobial Resistance Monitoring Group (SO-ZI/ AMR) occurs in the German study region.

Here, we analysed 2012 to 2016 MRSA surveillance data from Dutch and German border region hospitals (NL-BRH and DE-BRH) in the network in order to describe temporal and spatial trends of MRSA rates and find differences between these groups of hospitals. We also used the data to calculate the MRSA rates per inpatient and per patient days in both groups of hospitals and the MRSA rates per inhabitants in the patient catchment areas of NL-BRH and DE-BRH respectively in order to compare the two groups in relation to these parameters.

\section{Methods}

\section{Setting}

Within the EurSafety Health-net project (http:// www.eursafety.eu/) the German part of the project region geographically comprised six districts in the Münsterland region (codes DEA33-35, DEA37, DEA38 and DE94B, level 3, according to the Nomenclature of Territorial Units for Statistics, NUTS [16]) and was inhabited by ca 1.73 million people [17]. The Dutch part comprised eight districts in the provinces of Groningen, Drenthe and in the region Twente-Achterhoek (codes NL111-113, NL131-133, NL213 and NL225) inhabited by ca 2.10 million people (Figure) [17]. Initially, there were 42 hospitals located in the Dutch-German region (reduced in 2015 to 41 due to a structural merging of two DE-BRH) treating ca 620,000 admitted patients (68.0\% in the German part of the study region) with ca 3,900,000 patient days per year. All 34 (since 2015, 33) regional DE-BRH (9.5\% of hospitals in NRW in 2016) and all eight regional NL-BRH ( $8.8 \%$ of hospitals in the Netherlands in 2016) took part in the project. Among the DE-BRH, 29 were acute care hospitals, one was a university hospital, one was a rehabilitation clinic and three hospitals were specialised in psychiatry, while the NL-BRH comprised one university- and seven acute care hospitals. 
Annual medians of meticillin-resistant Staphylococcus aureus parameters in all study hospitals in the German region Münsterland and the Dutch regions of Twente-Achterhoek, Drenthe and Groningen, 2012-2016 ( $\mathrm{n}=42$ hospitals) ${ }^{\mathrm{a}}$

\begin{tabular}{|c|c|c|c|c|c|c|c|}
\hline \multirow{3}{*}{ Region, country (number of BRH) } & \multirow{3}{*}{ MRSA parameter } & \multicolumn{6}{|c|}{ Year(s) } \\
\hline & & 2012 & 2013 & 2014 & 2015 & 2016 & $2012-16$ \\
\hline & & $\begin{array}{l}\text { Median } \\
\text { (IQR) }\end{array}$ & $\begin{array}{l}\text { Median } \\
\text { (IQR) }\end{array}$ & $\begin{array}{c}\text { Median } \\
\text { (IQR) }\end{array}$ & $\begin{array}{l}\text { Median } \\
(\text { IQR })\end{array}$ & $\begin{array}{l}\text { Median } \\
(\text { IQR })\end{array}$ & $\mathrm{p}$ value \\
\hline \multirow{5}{*}{$\begin{array}{l}\text { Münsterland, Germany } \\
\text { (34 DE-BRH) }^{\mathrm{a}}\end{array}$} & $\begin{array}{c}\text { Nasopharyngeal swabs } \\
\text { for MRSA screening per } \\
\text { inpatients (\%) }\end{array}$ & $\begin{array}{c}37.7 \\
(31.6-54.7)\end{array}$ & $\begin{array}{c}40.3 \\
(33.9-51.1)\end{array}$ & $\begin{array}{c}43.6 \\
(31.7-55.1)\end{array}$ & $\begin{array}{c}44.1 \\
(35.8-57.1)\end{array}$ & $\begin{array}{c}47.4 \\
(38.4-63.5)\end{array}$ & 0.0006 \\
\hline & $\begin{array}{l}\text { MRSA cases } / 100 \\
\text { inpatients }\end{array}$ & $\begin{array}{c}1.1 \\
(0.8-1.6)\end{array}$ & $\begin{array}{c}1.0 \\
(0.7-1.3)\end{array}$ & $1.0(0.7-1.4)$ & $\begin{array}{c}1.1 \\
(0.8-1.3)\end{array}$ & $\begin{array}{c}0.9 \\
(0.8-1.3)\end{array}$ & 0.0814 \\
\hline & MRSAB/SAB (\%) & $\begin{array}{c}12.5 \\
(2.9-25.0) \\
\end{array}$ & $\begin{array}{c}14.3 \\
(6.3-25.0) \\
\end{array}$ & $\begin{array}{c}10.5 \\
(4.0-25.0) \\
\end{array}$ & $\begin{array}{c}9.8 \\
(2.6-28.6) \\
\end{array}$ & $\begin{array}{c}5.0 \\
(0.0-10.7) \\
\end{array}$ & 0.0959 \\
\hline & $\begin{array}{c}\text { MRSAB/100,000 patient } \\
\text { days }\end{array}$ & $\begin{array}{c}1.3 \\
(0.0-2.8) \\
\end{array}$ & $\begin{array}{c}2.6 \\
(0.0-4.9) \\
\end{array}$ & $1.7(0.0-2.7)$ & $\begin{array}{c}1.2 \\
(0.0-3.0) \\
\end{array}$ & $\begin{array}{c}1.5 \\
(0.0-2.8) \\
\end{array}$ & 0.4272 \\
\hline & $\begin{array}{c}\text { Nosocomial MRSA } \\
\text { cases } / 1,000 \text { patient } \\
\text { days }^{\mathrm{b}}\end{array}$ & $\begin{array}{c}0.11 \\
(0.06-0.18)\end{array}$ & $\begin{array}{c}0.09 \\
(0.04-0.16)\end{array}$ & $\begin{array}{c}0.09 \\
(0.03-0.14)\end{array}$ & $\mid \begin{array}{c}0.08 \\
(0.03-0.12)\end{array}$ & $\begin{array}{c}0.07 \\
(0.02-0.13)\end{array}$ & 0.0184 \\
\hline \multirow{5}{*}{$\begin{array}{l}\text { Twente-Achterhoek/Drenthe/ } \\
\text { Groningen, Netherlands } \\
\text { (8 NL-BRH) }\end{array}$} & $\begin{array}{c}\text { Nasopharyngeal swabs } \\
\text { for MRSA screening per } \\
\text { inpatients (\%) }\end{array}$ & $\begin{array}{c}2.05 \\
(0.65-4.10)\end{array}$ & $\begin{array}{c}3.65 \\
(0.65-4.60)\end{array}$ & $\begin{array}{c}2.80 \\
(0.65-4.65)\end{array}$ & $\begin{array}{c}3.55 \\
(0.60-7.20)\end{array}$ & $\begin{array}{c}5.45 \\
(0.85-10.05)\end{array}$ & 0.0188 \\
\hline & $\begin{array}{l}\text { MRSA cases } / 100 \\
\text { inpatients }\end{array}$ & $\begin{array}{c}0.11 \\
(0.09-0.13) \\
\end{array}$ & $\begin{array}{c}0.13 \\
(0.10-0.14) \\
\end{array}$ & $\begin{array}{c}0.12 \\
(0.09-0.16)\end{array}$ & $\begin{array}{c}0.13 \\
(0.10-0.15) \\
\end{array}$ & $\begin{array}{c}0.17 \\
(0.11-0.25)\end{array}$ & 0.0816 \\
\hline & MRSAB/SAB (\%) & $\begin{array}{c}0.7 \\
(0.0-3.4) \\
\end{array}$ & $\begin{array}{c}1.6 \\
(0.0-4 \cdot 3) \\
\end{array}$ & $1.0(0.0-5.0$ & $\begin{array}{c}1.9 \\
(0.0-4.3) \\
\end{array}$ & $\begin{array}{c}0.0 \\
(0.0-1.3)\end{array}$ & 0.1679 \\
\hline & $\begin{array}{c}\text { MRSAB/100,000 patient } \\
\text { days }\end{array}$ & $\begin{array}{c}0.3 \\
(0.0-1.3)\end{array}$ & $\begin{array}{c}0.6 \\
(0.0-1.9)\end{array}$ & $\begin{array}{c}0.6 \\
(0.0-2.0)\end{array}$ & $\begin{array}{c}1.0 \\
(0.0-1.9)\end{array}$ & $\begin{array}{c}0.0 \\
(0.0-0.6)\end{array}$ & 0.0620 \\
\hline & $\begin{array}{c}\text { Nosocomial MRSA } \\
\text { cases } / 1,000 \text { patient } \\
\text { days }^{\text {b }}\end{array}$ & $\begin{array}{c}0.03 \\
(0.02-0.04)\end{array}$ & $\begin{array}{c}0.025 \\
(0.020- \\
0.035)\end{array}$ & $\begin{array}{c}0.035 \\
(0.030- \\
0.055)\end{array}$ & $\begin{array}{c}0.030 \\
(0.020- \\
0.045)\end{array}$ & $\begin{array}{l}0.015 \\
(0.005- \\
0.030)\end{array}$ & $0.3532^{b}$ \\
\hline
\end{tabular}

BRH: border region hospitals; DE-BRH: German BRH; IQR: interquartile range; MRSA: meticillin-resistant Staphylococcus aureus; MRSAB: MRSA isolated from blood cultures; NL-BRH: Dutch BRH; SAB: S. aureus isolated from blood cultures.

a Since 2015 the number of DE-BRH was reduced to 33. This implies that the total number of hospitals in the study region became 41 after 2015.

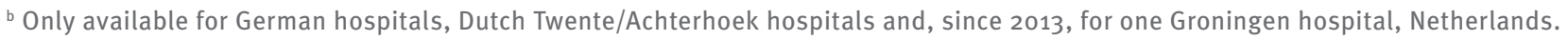

Guidelines for patients at risk for meticillinresistant Staphylococcus aureus and infection prevention and control measures

Both NL-BRH and DE-BRH implemented MRSA-related IPC measures according to their national guidelines and recommendations, issued by the Dutch Working Group on Infection Prevention (WIP) and the German Commission for Hospital Hygiene and Infection Prevention (KRINKO) at the Robert Koch-Institute, respectively $[10,18]$. Of note, the definitions of whom to screen at admission differed for NL-BRH and DE-BRH based on the national guidelines and recommendations (Table 1), as well as screening sites (DE-BRH: at least nose, pharynx, throat and wounds, if present, additionally perineum and groin swab, when indicated; NL-BRH: nasal-, throat- and perineum or rectum swab plus additional cultures depending on clinical signs) $[10,19]$. In all hospitals positive screenings or any other detection of MRSA was followed by single room isolation, contact precautions and decolonisation, if applicable. Pre-emptive isolation of patients with MRSA risk factors was performed according to local guidelines (in DE-BRH only for patients with previous MRSA carriage, for NL-BRH see Table 1. In both countries adherence to the MRSA-IPC guidelines- and recommendations was periodically checked by the responsible local public health authorities (Germany) and national health inspectorate (Netherlands). The implementation of other IPC measures in the participating hospitals, such as standards for the prevention of catheter-related bloodstream infections, was not planned or assessed within the project.

\section{Data collection}

An MRSA case was defined as an inpatient who was colonised or infected with MRSA at admission or for nosocomial MRSA cases, after admission. A blood culture positive for MRSA, from a single inpatient and from a single hospital stay was qualified as MRSAB case. If an MRSA case, or MRSAB case, had several stays in a year, each hospital stay was counted as an MRSA case, or MRSAB case, in the surveillance.

On both sides of the border, the collected surveillance data of inpatients (i.e. excluding outpatients) included the number of nasopharyngeal swabs performed for MRSA screening before or at admission, the numbers of MRSA cases (one isolate per patient per hospital 
Meticillin-resistant Staphylococcus aureus parameters in all study hospitals in the German region of Münsterland and the Dutch regions of Twente-Achterhoek, Drenthe and Groningen, 2012-2016 ( $\mathrm{n}=42$ hospitals) ${ }^{\mathrm{a}}$

\begin{tabular}{|c|c|c|c|c|c|}
\hline \multirow[t]{2}{*}{ Parameter } & \multicolumn{2}{|c|}{$\begin{array}{l}\text { Münsterland, Germany } \\
\qquad(34 \mathrm{DE}-\mathrm{BRH})^{\mathrm{a}}\end{array}$} & \multicolumn{2}{|c|}{$\begin{array}{l}\text { Twente-Achterhoek, Drenthe, } \\
\text { Groningen, Netherlands } \\
\text { (8 NL-BRH) }{ }^{\mathrm{a}}\end{array}$} & \multirow[t]{2}{*}{$\begin{array}{l}\text { p value (median } \\
\text { comparison) }\end{array}$} \\
\hline & Mean $^{b}$ & Median (IQR) & Mean ${ }^{b}$ & Median (IQR) & \\
\hline $\begin{array}{l}\text { Nasopharyngeal swabs for MRSA } \\
\text { screening/100 inpatients (\%) }\end{array}$ & 50.2 & $42.3(33.8-56.8)$ & 3.9 & $3.0(0.6-5.1)$ & $<0.0001$ \\
\hline $\begin{array}{l}\text { MRSA cases of colonisation and/or } \\
\text { infection/100 inpatients }\end{array}$ & 1.04 & $1.04(0.77-1.36)$ & 0.15 & $0.14(0.10-0.20)$ & $<0.0001$ \\
\hline MRSAB/SAB (\%) & 9.8 & $10.2(3.0-21.5)$ & 1.5 & $0.3(0.0-4.0)$ & $<0.0001$ \\
\hline MRSAB/100,000 patient days & 2.30 & $1.55(0.00-3.53)$ & 0.83 & $0.26(0.00-1.72)$ & 0.0041 \\
\hline $\begin{array}{l}\text { Nosocomial MRSA cases/1,000 patient } \\
\text { days }^{c}\end{array}$ & 0.11 & $0.09(0.03-0.14)$ & 0.03 & $0.03(0.02-0.04)$ & 0.0002 \\
\hline LOS in the hospital & 6.9 & $6.8(5.7-9.4)$ & $5 \cdot 3$ & $4.9(4.7-5.4)$ & $<0.0001$ \\
\hline LOS of MRSA patients ${ }^{d}$ & 11.4 & $11.1(8.5-14.2)$ & 12.1 & $11.7(5.6-17.5)$ & 0.8774 \\
\hline
\end{tabular}

DE-BRH: German border region hospitals; IQR: interquartile range; LOS: length of stay; MRSA: meticillin-resistant Staphylococcus aureus; MRSAB: MRSA isolated from blood cultures; NL-BRH: Dutch border region hospitals; SAB: $S$. aureus isolated from blood cultures.

a Since 2015 the number of DE-BRH was reduced to 33. This implies that the total number of hospitals in the study region became 41 after 2015.

b Pooled mean value.

' Only available for German hospitals, Dutch Twente-Achterhoek hospitals and, since 2013, for one Groningen hospital, Netherlands.

d Only available for German hospitals, two Dutch Twente-Achterhoek and two Groningen hospitals.

stay) - in DE-BRH and in several NL-BRH MRSA cases were additionally classified as imported or nosocomial (i.e. nosocomial, if the case was detected $\geq 3$ days after hospital admission unless the patient was a known MRSA carrier), the number of cases and the number of patient days. Additionally, in DE-BRH and in several NL-BRH the patient days of MRSA cases (i.e. the number of days, which an MRSA-positive patient spent in hospital) were also recorded. Moreover, the number of inpatients with a blood culture positive for MRSA (MRSAB, one isolate per patient case) and the number of $S$. aureus in blood cultures (one isolate per patient case) were assessed. The MRSA-surveillance data as described above were collected in all DE-BRH using a protocol adapted from the national German Nosocomial Infections Surveillance System (MRSAKISS [20]); see Supplement Table S1). For cross-border analysis, the laboratories serving for all NL-BRH provided retrospectively collected data for the period 2012 to 2016 , according to the same protocol.

\section{Ethical statement}

Ethical approval was asked from ethical committee at the University Medical Center Groningen (UMCG) and approval was not necessary for this study.

\section{Data analysis}

We analysed the surveillance data of 5 years (2012-16) and calculated the following parameters: (i) screening rate (nasopharyngeal swabs for MRSA/100 inpatients), (ii) MRSA incidence (MRSA cases/10o inpatients), (iii) percentage of MRSA isolates per all $S$. aureus isolates detected in blood cultures, (iv) incidence density of
MRSA isolates detected from blood cultures (MRSAB cases/100,000 patient days), (v) nosocomial MRSA incidence density (nosocomial MRSA-cases/1,000 patient days), (vi) length of stay in hospital (number of patient days/inpatients, (vii) length of stay in the hospital of MRSA cases (number of patient days of MRSA cases/MRSA cases). We calculated the mean annual numbers of inpatients per 100 inhabitants and of patient days per 100 inhabitants of the patient catchment area of NL-BRH and DE-BRH. Furthermore, we calculated the mean annual number of nasopharyngeal swabs performed for MRSA screening before or at admission to hospital per 100 inhabitants in the patient catchment area of the regional hospitals (DE-BR and NL-BR) as well as of inpatient MRSA cases per 1,000 inhabitants and the MRSAB/1,000,000 inhabitants using our surveillance data of inpatients (i.e. excluding outpatients). The number of inhabitants were assessed from the official statistical database [17].

Time trends of MRSA parameters were analysed by Friedman tests. The percentage of nosocomial MRSA cases on all MRSA cases was assessed by CochranArmitage test of linear trend. The cross-border regional comparisons were analysed using Wilcoxon rank sum test. All statistical analyses were done using SAS 9.4 software (SAS Institute Inc., Cary, United States); $p<0.05$ was considered significant. Results of significance tests were discarded if the software displayed an alert due to more than $10 \%$ of missing values in the respective dataset. The map was made using RegioGraph10 (GFK Geomarketing GmbH, Bruchsal, Germany). 
Calculated parameters in the patient catchment area of all study hospitals in the German region of Münsterland and Dutch regions of Twente-Achterhoek, Drenthe and Groningen, 2012-2016 ( $\mathrm{n}=42$ hospitals) ${ }^{\mathrm{a}}$

\begin{tabular}{|c|c|c|}
\hline Parameter & $\begin{array}{c}\text { Münsterland, Germany (DE-BR)a } \\
\text { Mean }^{c}\end{array}$ & $\begin{array}{c}\text { Twente-Achterhoek, Drenthe, } \\
\text { Groningen, Netherlands (NL-BR) } \\
\text { Meanc }^{\mathrm{b}}\end{array}$ \\
\hline Inpatients/10o inhabitants & 24.3 & 9.27 \\
\hline Patient days/100 inhabitants & 167.2 & 49.0 \\
\hline $\begin{array}{l}\text { Nasopharyngeal swabs for MRSA screening before or at admission } \\
\text { to hospital/100 inhabitants }\end{array}$ & 12.2 & 0.36 \\
\hline $\begin{array}{l}\text { Inpatient MRSA cases of colonisation and/or infection/1,000 } \\
\text { inhabitants }\end{array}$ & 2.52 & 0.14 \\
\hline MRSAB/1,000,000 inhabitants & 38.4 & 4.09 \\
\hline
\end{tabular}

DE-BR: German border region; MRSA: meticillin-resistant Staphylococcus aureus; MRSAB: MRSA isolated from blood cultures.

a Patient catchment area of 34 (since 2015: 33) German border region hospitals. This implies that the total number of hospitals in the study region became 41 after 2015 .

b Patient catchment area of eight Dutch border region hospitals.

c Pooled mean value.

\section{Results}

Trend and cross-border comparison of meticillin-resistant Staphylococcus aureus rates The total numbers of MRSA cases (detected in DE-BRH and NL-BRH are shown in Table 2. In both DE-BRH and $\mathrm{NL}-\mathrm{BRH}$ the median nasopharyngeal MRSA screening rate increased significantly between 2012 and 2016 (Table 3). Overall, the median screening rate was 14 times higher in DE-BRH than in NL-BRH ( $p<0.0001$, Table 4).

The median MRSA incidence remained stable over time at both sides of the border (Table 3), but was more than seven times higher in DE-BRH than in NL-BRH ( $p<0.0001)$ (Table 4). The median percentage of MRSA on $S$. aureus blood culture isolates decreased from $12.5 \%$ in 2012 to $5.0 \%$ in 2016 in DE-BRH $(p=0.0959)$, while it remained stable in NL-BRH $(p=0.1679)$ (Table 3$)$, but was more than 34 times higher in DE-BRH $(p=0.0001)$ (Table 4). The median of MRSAB per 100,000 patient days remained stable over time in DE-BRH $(p=0.4272)$ and NL-BRH $(p=0.0620)$ (Table 3$)$ and was six fold greater in DE-BRH than in NL BRH $(p=0.0041)$ (Table 4). The percentages of nosocomial cases on all MRSA cases (Table 2) decreased significantly in DE-BRH ( $p<0.0001)$, but did not change in NL-BRH ( $p<0.6474)$. Over the study period the median nosocomial MRSA incidence-density decreased significantly in DE-BRH $(p=0.0184)$ (Table 3$)$, but did not change in NL-BRH $(p=0.3532)$ and was approximately three times higher in DE-BRH than in NL-BRH $(p=0.0002)$ (Table 4).

\section{Cross-border comparison of healthcare utilisation}

We compared the available data on healthcare utilisation in DE-BRH and NL-BRH. The median length of stay (LOS) in the hospital was 6.8 days in DE-BRH compared with 4.9 days in NL-BRH $(p<0.0001)$ (Table 4$)$; LOS of MRSA patients was similar in DE-BRH vs NL-BRH (11.1 days vs 11.7 days; $p=0.8774$ ) (Table 4 ). The hospitalisation rate was 24.3 inpatients/100 inhabitants annually in the patient catchment area of DE-BRH, almost thrice the rate in the NL-BRH's catchment area (9.27/100). To put this difference in healthcare utilisation into context, we calculated the mean annual number of nasopharyngeal MRSA screening swabs before or at admission to hospital per 100 inhabitants in the German border region (DE-BR) vs the Dutch border region (NL-BR) (12.2 vs 0.36). Additionally, we compared the MRSA surveillance data of inpatients (i.e. excluding outpatients) in the patient catchment area of DE-BRH and NL-BRH. The calculated the number of inpatient MRSA cases per 1,000 inhabitants in DE-BR and NL-BR were 2.52 vs 0.14 . Furthermore, the calculated MRSAB/1,000,000 inhabitants in DE-BR and NL-BR was 38.4 vs 4.09 (Table 5).

\section{Discussion}

As patients in the EU have the right to healthcare across the borders of Member States (EU directive $2011 / 24 / E U)$, it is of interest to compare the quality of care, safety standards and risks of nosocomial infection by AMR pathogens between EU countries. In this respect, the cross-border systematic and continuous MRSA surveillance is one of the cornerstones to ensure equal quality of healthcare [21].

Our study revealed significant differences between Dutch and German hospitals (Table 4). The median MRSA-incidence in DE-BRH was more than seven times higher compared with NL-BRH. We also found that the median MRSA percentage of $S$. aureus detected in blood cultures was more than 34 times higher in DE-BRH than in NL-BRH (Table 4). The incidence density of MRSAB was six times higher in DE-BRH (Table 4) and there were nine times more MRSAB per 1,000,000 
inhabitants for the patient catchment area of DE-BRH compared with NL-BRH (Table 5).

According to the ECDC, differences in the occurrence of AMR pathogens between European countries are most likely caused by differences in healthcare utilisation, antimicrobial use and IPC practices [3].

Concerning healthcare utilisation in our context, we found that inhabitants in the German part of the study region were almost three times as often hospitalised (Table 5) and had a significantly longer LOS than patients on the Dutch part (Table 4 ). This may be due to socioeconomic factors or a different organisation of ambulatory healthcare.

While antimicrobial consumption was not the focus of the current study, NRW has been reported as the region in Germany with the highest antimicrobial consumption in outpatients (19.2 daily defined doses (DDD/1,000 inhabitants) [22]. In this respect, the MRSA incidence in DE-BRH was slightly above the incidences in German hospitals participating in the nationwide surveillance system MRSA-KISS [20]. The antimicrobial consumption level in NRW seems to be also considerably higher than in the Netherlands (10.39 DDD/1,000 inhabitants) [23], not only in terms of total antibiotics consumed, but also for the oral use of second-generation cephalosporins. Promoting rational regional antibiotic use is therefore one of the major goals in the INTERREG VA project EurHealth-1Health (http://www.eurhealth1health.eu/).

For MRSA IPC, the recommendations in Germany and the corresponding guidelines in the Netherlands were comparable regarding the measures performed for MRSA carriers $[10,18]$. However, there were differences between the two countries in identifying people at risk of MRSA infection/colonisation $[10,18]$. In this study, we found that the DE-BRH performed 14 times more nasopharyngeal screening swabs for MRSA than their Dutch counterparts.

The higher screening rates on the German side of the border may be ascribed to the fact that in German IPC recommendations, previous hospitalisation in Germany is a risk factor for MRSA carriage. This constitutes a main difference in defined risk factors between Dutch- and German MRSA IPC guidelines, whereby Dutch guidelines mostly consider screening for patients previously hospitalised outside the Netherlands (Tables 1 and 3 ) $[14,24]$. In this respect, we observed that although the densities of nosocomial MRSA cases were lower in NL-BRH than in DE-BRH (Table 3), the proportion of nosocomial MRSA cases among all MRSA detected was slightly higher in the Dutch hospitals (Table 2). The reason for this remains unclear, but it might be speculated that a larger proportion of MRSA carriers in the Netherlands had no risk factors for MRSA and were hence not screened at admission.
Another explanation for screening rate differences between the two countries may be distinct underlying epidemiological situations regarding MRSA. For example, the MRSA prevalence is higher in the population in Germany than that in patients at hospital admission in the Netherlands (0.7\% vs. 0.13\%) [25,26]. Moreover in the German part of the study region, a possible additional MRSA burden due to the exceptionally frequent occurrence of livestock-associated MRSA might have an effect $[27,28]$.

The screening and IPC measures in the DE-BRH appeared to be nevertheless appropriate. In 2006, in the project region excluding Groningen and Drenthe (Figure), investigations evaluating the numbers of patients with MRSA risk factors at admission to German hospitals demonstrated that ca $35.6 \%$ of patients had a risk factor requiring screening [29]. A corresponding level of screening was implemented by DE-BRH during the study period 2009-11 [15]. This level remained high in the 2012-16 period (Table 3), indicating a very good implementation of the screening standards.

About $1 \%$ of all patients admitted in DE-BRH carried MRSA, which corresponds well to results of investigations evaluating the prevalence of MRSA carriage in the regional general, non-hospitalised population in 2012 [25]. In terms of difference with the Netherlands, this has for consequence that it is more expensive to provide isolation capacities for ca $1.0 \%$ of inpatients with MRSA in DE-BRH vs $0.15 \%$ in NL-BRH. Moreover, the higher MRSA incidence in DE-BRH could lead to a higher probability for nosocomial MRSA cases as they are not completely avoidable [30-32].

From 2012 to 2016 however, the nosocomial MRSA incidence density in DE-BRH decreased significantly, a trend already observed from 2009 to 2011 [15]. Moreover, the nosocomial MRSA incidence density (Table 3) appeared to be below the densities reported for hospitals participating in the nationwide surveillance system MRSA-KISS (median nosocomial MRSA cases per 1,000 patient days in DE-BRH/MRSA KISS, 2012-16: 0.11/0.14, 0.09/0.12, 0.09/0.10, 0.08/0.09, $0.07 / 0.08)[15,20]$. This may indicate the successful implementation of concerted IPC standards in DE-BRH in the EurSafety Health-net network [15].

We also observed for that the difference of the incidence of MRSA bacteraemia per inhabitants between the German and Dutch border region (38.4 vs 4.09 per 1,000,000) was apparently smaller than calculated in a previous study, which used 2009 Dutch and 2010 German data respectively to derive the difference between NRW and the Netherlands (57.6 vs 1.8 per $1,000,000$ ) [5]. In addition, according to the population-based German mandatory notification system for invasive MRSA infections (SurvStat) from 2012 to 2016, 40.7 MRSA isolates were detected in blood or cerebrospinal fluid per 1,000,000 inhabitants in the German project region [33], which is lower compared 
with data from the federal state of NRW (70.3 per 1,000,000 inhabitants) as well as from Germany (47.9 per 1,000,000 inhabitants) [34].

Comparing our results with those of other German laboratories participating in a voluntary, national surveillance system (ARS) [35], revealed that, for each year of the period 2012-16 the median percentage of MRSA in $S$. aureusfrom blood cultures was lower in DE-BRH than in other laboratories in western Germany (DE-BRH/ ARS-region west (NRW), 2012-16: 12.5\%/19.0\%, $14.3 \% / 15.0 \%$, $10.5 \% / 13.5 \%$, 9.8\%/13.3\%, 5.0\%/12.0\%) (Table 3), as well as below the middle lower range of the EU/European Economic Association (EEA) population-weighted mean between $18.8 \%$ in 2012 and $13.7 \%$ in 2016 [3,34,36].

In contrast, the mean MRSA percentage of $S$. aureus detected in blood culture during 2012-16 was higher (1.5\% vs $1.3 \%$ ) in NL-BRH compared with Dutch national data of Infectious Disease Surveillance Information System for Antibiotic Resistance, (ISIS-AR) covering data of $52 \%$ of diagnostic laboratories [37].

As typical for all passive surveillance systems, bias due to differences in reporting behaviour cannot be excluded and is a limitation of this study. However, as MRSA surveillance in DE-BRH started in 2007, a stabilised compliance in reporting can be assumed for the period from 2012-16. The higher number of MRSA cases per inhabitants on the German side compared with the Netherlands is biased if there is more than one episode of MRSA detection per year for one individual patient among the number of cases. Also the inclusion of three psychiatric hospitals and one rehabilitation clinic, which have usually longer average lengths of stay, may have prolonged hospital stay in the DE-BRH. However, the data are in accordance with German-wide assessment systems. The clinical relevance of MRSA isolates detected in blood cultures is undisputable, but variations in blood culture diagnostics (e.g. frequency, performance) may result in bias when comparing MRSA percentages of $S$. aureus blood culture isolates between different countries [38]. A limitation of the study design is that the implementation of IPC standards, which are not directly targeted to control MRSA, such as bundles to prevent central-lineassociated bloodstream infections (CLABSI), was not assessed and compared in the participating hospitals. Hence, changes of the incidence of MRSA bacteraemia could also be attributable to improvements in CLABSI prevention or other IPC standards.

This study on MRSA covering all hospitals across part of a European border as well as hospitals of all three care-categories demonstrated that routine MRSA surveillance may be helpful to monitor trends of MRSA parameters, to compare the MRSA rates and to indicate needs for further improvement to reach low MRSA rates EU-wide. Our results supplement the European and national surveillance systems. Ongoing efforts in MRSA prevention are recommended, including all healthcare sectors, especially with focus on One Health [39-42]. Moreover, cross-border surveillance should be extended to other multidrug-resistant organisms, such as CR Enterobacteriaceae in the future.

\section{Acknowledgements}

We acknowledge all the active participants of the EurSafety Health-net and EurHealth-1Health projects: The infection control nurses and the physicians responsible for infection control of the 42 participating hospitals, as well as the staff of the regional laboratories participating in the project. We thank the project representatives appointed by the public health offices in the EUREGIO, especially Ms. Scherwinski and Ms. Winkler (both Borken), Dr. Toepper (Coesfeld), Dr. Bierbaum and Dr. Lürwer (both Münster), Dr. Schmeer and Ms. Suhr (both Steinfurt), Dr. König and Ms. Clemens (Warendorf). Furthermore, we thank Ms. Schmidt, Ms. Lunemann, Ms. Jessen and Ms. Ganser (NRW Centre for Health) and Dr. Gunnar Andriessen from CERTE in Groningen for their support.

Funding: The EurSafety Health-Net project was financially supported by external funding within the INTERREG IVA program 'Germany-Netherlands' of the EU (EurSafety Health-net: INTERREG IVA III-1-01=073), by the German states of NRW and Lower Saxony and by the Dutch provinces Overijssel, Gelderland and Limburg. The EurHealth-1Health project is implemented within the framework of the INTERREG VA 'Germany-Netherlands' program (grant number EU/INTERREG VA-202085) and is co-financed by the European Union, the Dutch Ministry of Health, Welfare and Sport (VWS), the Ministry of Economy, Innovation, Digitalisation and Energy of the German Federal State North Rhine-Westphalia and by the German Federal State Lower Saxony.

\section{Conflict of interest}

None declared.

\section{Authors' contributions}

AJ, RK, IDH and AWF conceived and designed the study. AJ, WS, AWF and RK performed the epidemiological analysis and interpreted the results. AJ, WS, MSB, KB, CG and AWF acquired the original data. AJ and AWF drafted and WS and RK critically revised the manuscript. IDH, WS, MSB, CG, KB, RK and AWF discussed and reviewed the draft manuscript and revised the elaborated recommendations. All authors approved the final version.

\section{References}

1. Poljak M, Akova M, Friedrich AW, Rodríguez-Baño J, Sanguinetti M, Tacconelli E, et al. ESCMID-an international Europe-based society committed to fostering cross-border collaboration and education to improve patient care. Clin Microbiol Infect. 2018;24(1):1-2. https://doi.org/10.1016/j. cmi.2017.05.024 PMID: 28583741

2. Cassini A, Högberg LD, Plachouras D, Quattrocchi A, Hoxha A, Simonsen GS, et al. Attributable deaths and disabilityadjusted life-years caused by infections with antibioticresistant bacteria in the EU and the European Economic Area in 2015: a population-level modelling analysis. Lancet Infect Dis. 2019;19(1):56-66. https://doi.org/10.1016/S14733099(18)30605-4 PMID: 30409683

3. European Centre for Disease Prevention and Control (ECDC). Antimicrobial resistance surveillance in Europe 2016. Annual 
Report of the European Antimicrobial Resistance Surveillance Network (EARS-Net). Stockholm: ECDC; 2017. Available from: https://ecdc.europa.eu/sites/portal/files/documents/AMRsurveillance-Europe-2016.pdf

4. European Centre for Disease Prevention and Control (ECDC). ECDC, EFSA and EMA Joint Scientific Opinion on a list of outcome indicators as regards surveillance of antimicrobial resistance and antimicrobial consumption in humans and foodproducing animals. EFSA J. 2017;15(10):5017.

5. van Cleef BAGL, Kluytmans JAJW, van Benthem BHB, Haenen A, Monen J, Daniels-Haardt I, et al. Cross border comparison of MRSA bacteraemia between The Netherlands and North Rhine-Westphalia (Germany): a cross-sectional study. PLoS One. 2012;7(8):e42787. https://doi.org/10.1371/journal. pone.0042787 PMID: 22880109

6. Köck R, Becker K, Cookson B, van Gemert-Pijnen JE, Harbarth $\mathrm{S}$, Kluytmans J, et al. Systematic literature analysis and review of targeted preventive measures to limit healthcare-associated infections by meticillin-resistant Staphylococcus aureus. Euro Surveill. 2014;19(29):23-49. https://doi.org/10.2807/15607917.ES2014.19.29.20860 PMID: 25080142

7. Sai N, Laurent C, Strale H, Denis O, Byl B. Efficacy of the decolonization of methicillin-resistant Staphylococcus aureus carriers in clinical practice. Antimicrob Resist Infect Control. 2015;4(56):56. https://doi.org/10.1186/s13756-015-0096-x PMID: 26688720

8. Sassmannshausen R, Deurenberg RH, Köck R, Hendrix R, Jurke A, Rossen JWA, et al. MRSA Prevalence and Associated Risk Factors among Health-Care Workers in Non-outbreak Situations in the Dutch-German EUREGIO. Front Microbiol. 2016;7(1273):1273. https://doi.org/10.3389/fmicb.2016.01273 PMID: 27597843

9. Dik JW, Sinha B, Friedrich AW, Lo-Ten-Foe JR, Hendrix R, Köck $R$, et al. Cross-border comparison of antibiotic prescriptions among children and adolescents between the north of the Netherlands and the north-west of Germany. Antimicrob Resist Infect Control. 2016;5(1):14. https://doi.org/10.1186/s13756016-0113-8 PMID: 27096086

10. Commission for Hospital Hygiene and Infection Prevention at Robert Koch-Institute. Empfehlungen zur Prävention und Kontrolle von Methicillin-resistenten Staphylococcus aureus-Stämmen (MRSA) in medizinischen und pflegerischen Einrichtungen. [Recommendations for prevention and control of methicillin-resistant Staphylococcus aureus (MRSA) in medical and nursing facilities]. Bundesgesundheitsblatt Gesundheitsforschung Gesundheitsschutz. 2014;57(6):695 732. German. https://doi.org/10.1007/s00103-014-1980-x

11. Commission for Hospital Hygiene and Infection Prevention at Robert Koch-Institute. Empfehlungen zur Prävention und Kontrolle von Methicillinresistenten Staphylococcus aureus-Stämmen (MRSA) in medizinischen und pflegerischen Einrichtungen. [Recommendations for the prevention and control of methicillin-resistant Staphylococcus aureus isolates (MRSA) in hospitals and other healthcare facilities]. GMS Krankenhhyg Interdiszip. 2009;4(1):Doc01. PMID: 20204101

12. Friedrich AW, Daniels-Haardt I, Köck R, Verhoeven F, Mellmann A, Harmsen D, et al. EUREGIO MRSA-net Twente/Münsterland-a Dutch-German cross-border network for the prevention and control of infections caused by methicillin-resistant Staphylococcus aureus. Euro Surveill. 2008;13(35):18965. https://doi.org/10.2807/ese.13.35.18965-en PMID: 18761882

13. Ciccolini M, Donker T, Köck R, Mielke M, Hendrix R, Jurke A, et al. Infection prevention in a connected world: the case for a regional approach. Int J Med Microbiol. 2013;303(6-7):380-7 https://doi.org/10.1016/j.ijmm.2013.02.003 PMID: 23499307

14. Souverein D, Houtman P, Euser SM, Herpers BL, Kluytmans J, Den Boer JW. Costs and Benefits Associated with the MRSA Search and Destroy Policy in a Hospital in the Region Kennemerland, The Netherlands. PLoS One. 2016;11(2):e0148175. https://doi.org/10.1371/journal. pone.0148175 PMID: 26849655

15. Jurke A, Köck R, Becker K, Thole S, Hendrix R, Rossen J, et al. Reduction of the nosocomial meticillin-resistant Staphylococcus aureus incidence density by a region-wide search and follow-strategy in forty German hospitals of the EUREGIO, 2009 to 2011. Euro Surveill. 2013;18(36):20579. https://doi.org/10.2807/1560-7917.ES2013.18.36.20579 PMID: 24079380

16. Eurostat. Nomenclature of territorial units for statistics (NUTS); National structures (EU). Eurostat; 2018. Available from: https://ec.europa.eu/eurostat/web/nuts/ national-structures-eu

17. Eurostat. Population density by NUTS 3 region. Eurostat: 2018. Available from: https://ec.europa.eu/eurostat/web/ products-datasets/product?code $=$ demo_r_dzdens

18. Werkgroep Infectiepreventie (WIP). Meticilline-resistente Staphylococcus aureus (MRSA) - Ziekenhuizen [
Meticilline-resistente Staphylococcus aureus (MRSA) hospitals]. Leiden; WIP; 2012. Dutch. Available from: http:// www.rivm.nl/dsresource?objectid=3fo54354-ff4a-43ef-91f9-7c6 fo417be95\&type=org\&disposition=inline

19. Nederlandse Vereniging voor Medische Microbiologie (NVMM). NVvMM - richtlijn [Dutch Society for Medical MicrobiologyGuideline: Laboratory detection of highly resistant microorganisms (HRMO) version 2.0]. Leeuwarden; NVMM; 2012. [Accessed 03 Feb 2019]. Available from: https://www. nvmm.nl/media/1051/2012_hrmo_mrsa_esbl.pdf.

20. Surveillance NI. MRSA-KISS-Protocoll-2016; MRSA KISS Reference data 2016. [Accessed o3 Feb 2019]. Available from: https://www.nrz-hygiene.de/surveillance/kiss/mrsa-kiss/ archiv/ 2017.

21. European Commission. Communication from the Commission to the European Parliament and the Council. Action plan against the rising threats from Antimicrobial Resistance. Brüssel: Publications Office of the European Union; 2011. Available from: https://www.eumonitor.eu/9353000/1/ j4nvke1fm2yd1uo_j9vvik7m1c3gyxp/vkcwedxv7dzy/v=s7z/f=/ com(2011)748_en.pdf

22. (PEG) P-E-GfC. GERMAP 2015 - Bericht über den Antibiotikaverbrauch und die Verbreitung von Antibiotikaresistenzen in der Human- und Veterinärmedizin in Deutschland. Rheinbach: Antiinfectives Intelligence; 2016. Report No.: 978-3-9818383-0-5. Available from: http://www.pe-g.org/econtext/germap

23. SWAB. NethMap 2017, Consumption of antimicrobial agents and antimicrobial resistance among medically important bacteria in The Netherlands in 2016. MARAN 2017, Monitoring of Antimicrobial Resistance and Antibiotic Usage in Animals in the Netherlands in 2016. Bergen; 2019. Available from: https:// www.rivm.nl/bibliotheek/rapporten/2017-0056.pdf

24. van der Zee A, Hendriks WD, Roorda L, Ossewaarde JM, Buitenwerf J. Review of a major epidemic of methicillinresistant Staphylococcus aureus: the costs of screening and consequences of outbreak management. Am J Infect Control. 2013;41(3):204-9. https://doi.org/10.1016/j.ajic.2012.02.033 PMID: 22921104

25. Köck R, Werner P, Friedrich AW, Fegeler C, Becker KPrevalence of Multiresistant Microorganisms (PMM) Study GroupPrevalence of Multiresistant Microorganisms PMM Study Group. Persistence of nasal colonization with human pathogenic bacteria and associated antimicrobial resistance in the German general population. New Microbes New Infect. 2015;9:24-34. https://doi.org/10.1016/j.nmni.2015.11.004 PMID: 26862431

26. Weterings V, Veenemans J, van Rijen M, Kluytmans J. Prevalence of nasal carriage of methicillin-resistant Staphylococcus aureus in patients at hospital admission in the Netherlands, 2010 - 2017: an observational study. Clin Microbiol Infect. 2019;S1198-743X(19)30114-4. https://doi. org/10.1016/j.cmi.2019.03.012 PMID: 30928560

27. Köck R, Schaumburg F, Mellmann A, Köksal M, Jurke A, Becker K, et al. Livestock-associated methicillin-resistant Staphylococcus aureus (MRSA) as causes of human infection and colonization in Germany. PLoS One. 2013;8(2):e55040. https://doi.org/10.1371/journal.pone.0055040 PMID: 23418434

28. Schaumburg F, Köck R, Mellmann A, Richter L, Hasenberg F, Kriegeskorte A, et al. study group. Population dynamics among methicillin-resistant Staphylococcus aureus isolates in Germany during a 6-year period. J Clin Microbiol. 2012;50(10):3186-92. https://doi.org/10.1128/JCM.01174-12 PMID: 22814464

29. Köck R, Brakensiek L, Mellmann A, Kipp F, Henderikx M, Harmsen D, et al. Cross-border comparison of the admission prevalence and clonal structure of meticillin-resistant Staphylococcus aureus. J Hosp Infect. 2009;71(4):320-6. https://doi.org/10.1016/j.jhin.2008.12.001 PMID: 19201056

30. Haley RW. Surveillance by objective: a new priority-directed approach to the control of nosocomial infections. The National Foundation for Infectious Diseases lecture. Am J Infect Control. 1985;13(2):78-89. https://doi.org/10.1016/01966553(85)90085-9 PMID: 3846430

31. Gastmeier P, Bräuer H, Forster D, Dietz E, Daschner F, Rüden $\mathrm{H}$. A quality management project in 8 selected hospitals to reduce nosocomial infections: a prospective, controlled study. Infect Control Hosp Epidemiol. 2002;23(2):91-7. https://doi. org/10.1086/502013 PMID: 11893154

32. Pronovost P, Needham D, Berenholtz S, Sinopoli D, Chu H, Cosgrove $S$, et al. An intervention to decrease catheterrelated bloodstream infections in the ICU. N Engl J Med. 2006;355(26):2725-32. https://doi.org/10.1056/NEJMoao61115 PMID: 17192537 
33. Robert-Koch-Institute. Surveillance Statistics (Germany). SurvStat@RKI 2.0. [Accessed o3 Feb 2019]. Available from: https://survstat.rki.de

34. Walter J, Haller S, Blank HP, Eckmanns T, Abu Sin M, Hermes J. Incidence of invasive meticillin-resistant Staphylococcus aureus infections in Germany, 2010 to 2014. Euro Surveill. 2015;20(46):30067. https://doi.org/10.2807/1560-7917. ES.2015.20.46.30067 PMID: 26607355

35. Robert-Koch-Institute. Antimicrobial Resistance Surveillance (ARS, Germany). [Accessed 03 Feb 2019]. Available from: https://ars.rki.de

36. Olearo F, Albrich WC, Vernaz N, Harbarth S, Kronenberg ASwiss Centre For Antibiotic Resistance Anresis. Staphylococcus aureus and methicillin resistance in Switzerland: regional differences and trends from 2004 to 2014. Swiss Med Wkly. 2016;146:W14339. https://doi.org/10.4414/smw.2016.14339 PMID: 27631162

37. NVMM. Infectieziekten Surveillance Informatie Systeem Antibiotica Resistentie (ISIS-AR). [Accessed 03 Feb 2019]. Available from: https://www.isis-web.nl

38. Raupach-Rosin H, Duddeck A, Gehrlich M, Helmke C, Huebner J, Pletz MW, et al. Deficits in knowledge, attitude, and practice towards blood culture sampling: results of a nationwide mixedmethods study among inpatient care physicians in Germany. Infection. 2017;45(4):433-41. https://doi.org/10.1007/s15010017-0990-7 PMID: 28205159

39. Köck R, Kreienbrock L, van Duijkeren E, Schwarz S. Antimicrobial resistance at the interface of human and veterinary medicine. Vet Microbiol. 2017;200:1-5. https://doi. org/10.1016/j.vetmic.2016.11.013 PMID: 27916320

40. Maier GS, Thorey F, Kolbow K, Lazovic D, Lühmann M, Ohnsorge J, et al. Livestock-assoziierter Methicillin-resistenter Staphylococcus aureus - Erhebung einer orthopädischen Fachklinik im Hochrisikogebiet Nord-West. [LivestockAssociated Methicillin-Resistant Staphylococcus aureus: Epidemiological Data from an Orthopaedic Department in North-West Germany]. Z Orthop Unfall. 2017;155(3):304-9. PMID: 28431450

41. Nillius D, von Müller L, Wagenpfeil S, Klein R, Herrmann M. Methicillin-Resistant Staphylococcus aureus in Saarland, Germany: The Long-Term Care Facility Study. PLoS One. 2016;11(4):e0153030. https://doi.org/10.1371/journal. pone.0153030 PMID: 27073899

42. Paget J, Aangenend $H$, Kühn $M$, Hautvast J, van Oorschot $D$, Olde Loohuis A, et al. MRSA Carriage in Community Outpatients: A Cross-Sectional Prevalence Study in a HighDensity Livestock Farming Area along the Dutch-German Border. PLoS One. 2015;10(11):e0139589. https://doi. org/10.1371/journal.pone.0139589 PMID: 26619190

\section{License, supplementary material and copyright}

This is an open-access article distributed under the terms of the Creative Commons Attribution (CC BY 4.0) Licence. You may share and adapt the material, but must give appropriate credit to the source, provide a link to the licence and indicate if changes were made.

Any supplementary material referenced in the article can be found in the online version.

This article is copyright of the authors or their affiliated institutions, 2019. 